\title{
Post Hysterectomy morbidity: a suburban teaching hospital experience in Kanchipuram, Tamil Nadu, South India
}

\author{
P. Vijaya Lakshmi, Wills G. Sheela*, M. Mohanambal Munusamy
} Department of Obstetrics and Gynaecology, Shri Sathya Sai Medical College and Research Institute, Ammapettai,
Kancheepuram, Tamil Nadu, India

Received: 15 August 2017

Accepted: 09 September 2017

\section{*Correspondence:}

Dr. Wills G. Sheela,

E-mail: drgwillssheelaa@yahoo.in

Copyright: (C) the author(s), publisher and licensee Medip Academy. This is an open-access article distributed under the terms of the Creative Commons Attribution Non-Commercial License, which permits unrestricted non-commercial use, distribution, and reproduction in any medium, provided the original work is properly cited.

\begin{abstract}
Background: Hysterectomy is the removal of uterus for benign uterine tumor and uterine descent in perimenopausal women. Post hysterectomy and follow up morbidity in rural women is studied over a period of 1 year. They were reviewed during hospital stay to identify morbidity and risk factors for prolonged hospital stay and formulate modalities to reduce morbidity. Risk factors assessed were fever, wound sepsis, anemia, previous post-operative adhesions and injury to other organs. Follow up was done at 4 weeks. $72 \%$ women were morbidity free. $46 \%$ women had more than one morbidity. The aim of this study is to analyse immediate and late post hysterectomy morbidity in a rural setup and to identify risk factors for prolonged hospitalization and formulate modalities to reduce morbidity and duration of hospital stay.

Method: Perimenopausal women who underwent hysterectomy for benign uterine conditions and uterine descent were studied for post-operative morbidity at SSSMCRI over a period of one year. Post hysterectomy morbidity was clinically assessed from day one of surgery till discharge, for early and late morbidity. Abdominal skin incision smear, vault smear, urine culture and USG pelvis for collection of fluid was done in woman who developed fever. Follow-up morbidity was done at 4 weeks. Hysterectomy done for malignant conditions were excluded from the study.

Results: In rural women, postoperative morbidity was assessed in 81 abdominal, 32 vaginal hysterectomy. Postoperative pain was felt by all 113 women for first 3 days. Fall of hemoglobin due to haemorrhage was seen in 43 $(38 \%)$ women. 33 needed post-operative blood transfusion. Surgical site infection was seen in 13, needed re-suturing in 7. Fever was seen in 50 women (44\%) due to UTI (E coli 13, Klebsiella 5). Pelvic fluid collection was seen in 9 with vault infection. We had one burst abdomen, one re-laparotomy, 3 bladder injuries. Prolonged hospital stay was seen in 41 women. $46 \%$ had more than one morbidity. Follow-up at 4 weeks, $72 \%$ were morbidity-free. Prolene granuloma 2, Stitch abscess 9, vaginal discharge 14, vault granuloma 3 were observed. Vaginal smear showed 9 Staphylococcus aureus and 5 bacterial vaginosis infection. 12 women had E. coli and 6 Klebsiella infection in urine culture.

Conclusion: Pre-operative risk factors for post op morbidity like anemia, urinary and vaginal infection should be properly treated prior to surgery. Awareness of risk factors for morbidity, anticipation of complications due to size, site, nature of tumour and previous surgery adhesions, timely intervention by experienced surgeons and adequate blood transfusion will reduce morbidity and prolonged hospital stay.
\end{abstract}

Keywords: Anemia, Bladder injury, Fever, Vault granuloma, Wound sepsis 


\section{INTRODUCTION}

Hysterectomy is removal of uterus for benign uterine conditions and uterine descent. It can be done by abdominal, vaginal and laparoscopic routes. Urban women prefer laparoscopy assisted vaginal hysterectomy. Vaginal hysterectomy is preferred by urban women for short hospital stay. Rural women prefer abdominal hysterectomy irrespective of age and type of gynecological problem. They are not aware of the consequences of excessive bleeding and lump in the abdomen and attribute it to approaching menopause. Hence often they present late to the hospital with severe anemia and massive abdominopelvic tumor and ovarian mass. ${ }^{1,2} 50$ percent of abdominal hysterectomy done in SSSMCRI, a rural tertiary care hospital in the suburban area of Kanchipuram, was for leiomyoma of varying size, site and number. ${ }^{3}$ The largest we operated was 32 weeks size, $4.5 \mathrm{~kg}$ intramural fibroid in a 42-year-old nulliparous woman who presented with pain abdomen. Another 35-year-old presented with secondary infertility had 21 small fibroids and 2 big $4 \times 5 \mathrm{~cm}$ submucous fibroids.

Aim of the present study was to assess the risk factors causing post-operative morbidity and to formulate modalities to prevent morbidity risk factors like pain, fever, anemia, wound sepsis and previous operative adhesions. ${ }^{1,2,4-6}$ Soft tissue injuries are directly proportional to increase in morbidity, surgery time, blood loss and hospital stay. ${ }^{3}$ Pre-operative assessment of anemia, size, site, number and nature of tumor and previous surgery is very important so that proper precautions can be taken prior to surgery. Necessary treatment to correct anemia, to arrange availability of experienced surgeons, when we anticipate complications due to previous surgery adhesions, size, site, number and tumor morphology is mandatory to prevent intraoperative and post-operative morbidity thereby reducing hospital stay. 3,7

\section{METHODS}

Perimenopausal women who underwent hysterectomy for benign uterine conditions and uterine descent over a period of one year in SSSMCRI at Ammapettai were registered as study subjects. Hysterectomy done for malignant conditions were not included in the study. This is a prospective hospital based observational study, conducted among rural women belonging to low socioeconomic strata. Clinical assessment for post-operative morbidity was done from day one of surgery to the day of discharge, for early and late morbidity in 113 women. Of these, 81 were abdominal hysterectomy and 32 vaginal hysterectomy. 46 fibroids, 17 adenomyosis, 15 DUB, 3 submucosal leiomyomatous polyps had abdominal hysterectomy. Twenty-two $3^{\text {rd }}$ degree uterine prolapse and 10 DUB with first degree uterine descent had vaginal hysterectomy. Pain, fever, wound sepsis, anemia, and intra operative complications like hemorrhage and injury to soft tissues, paralytics ileus were early morbidity factors. ${ }^{1-7}$ Relaparotomy was done in one woman within 12 hours for slippage of ligature. ${ }^{4}$ In women who had fever and wound infection, wound smear from skin incision was taken. For vaginal discharge, vaginal vault smear was taken. Urine for culture in women with urinary complaints was sent for culture and sensitivity. Pelvic fluid collection assessment, by USG was done in women with vault hematoma and vault cuff infection..$^{5,8-10}$

Follow-up morbidity was assessed at 4 weeks post operatively. Local examination of abdominal wound and vault inspection was done in all cases who came for follow-up. Vaginal vault and skin incision wound smear was taken in women who came with discharge. Urine culture was done in for urinary symptoms. 81 women were morbidity free.

\section{RESULTS}

Total number of hysterectomies done was 113. Abdominal 81 and vaginal 32. Indications for hysterectomies in perimenopausal women, was fibroid uterus 46 , adenomyosis 22 , DUB $13,3^{\text {rd }}$ degree uterine descent 22, DUB with first degree uterine descent 10.

Table 1: Pain morbidity $(\mathrm{n}=113)$.

\begin{tabular}{|llll|}
\hline Pain (113) & Post-op day & TAH & VH \\
\hline Severe & $1-3$ & 81 & 32 \\
\hline Moderate & $4-6$ & 60 & 20 \\
\hline No pain & 7 & 81 & 32 \\
\hline
\end{tabular}

All post op women had post-operative pain. In abdominal hysterectomy pain was very severe, patients walked with support on $3^{\text {rd }}$ day. Vaginal hysterectomy women walked without support on $2^{\text {nd }}$ day. They needed less analgesics.

Table 2: Early morbidity within 48 hours.

\begin{tabular}{|lll|}
\hline Morbidity & TAH $(\mathbf{8 1})$ & VH (32) \\
\hline Blood loss & & \\
\hline$>350 \mathrm{ml}$ & 26 & 7 \\
\hline $300-200 \mathrm{ml}$ & 30 & 11 \\
\hline$<150$ & 5 & 14 \\
\hline Blood transfusion & 26 & 7 \\
\hline Paralytic ileus & 6 & Nil \\
\hline Bladder injury & 2 & 1 \\
\hline Reopen abdomen & 1 & Nil \\
\hline Prolonged stay & 32 & 9 \\
\hline
\end{tabular}

Blood loss greater than $350 \mathrm{ml}$ in $26 \mathrm{TAH}$ and $7 \mathrm{VH}$ women (37.4\%). Average blood loss between 200-300 $\mathrm{ml}$ in 41 women and minimum loss in 19 women. 33 $(34.2 \%)$ needed blood transfusion. Paralytics ileus in 6. Relaparotomy 1 for intra-abdominal bleeding.

Smear from skin incision and vault was taken when women developed fever and wound infection. Smears 
were sent to Microbiology Department for culture and sensitivity. Klebsiella infection was seen in 4 women. The next common was $E$. coli in vault smear, bacterial vaginosis was seen in 5 subjects and $S$. aureus in 7 .

Table 3: Fever morbidity n=50 (44.2\%).

\begin{tabular}{|c|c|c|}
\hline Causes & $\begin{array}{l}\text { Number } \\
\text { of smears }\end{array}$ & Microorganisms \\
\hline \multirow{2}{*}{ Wound infection } & \multirow{2}{*}{13} & Staph epidermidis:10 \\
\hline & & E. coli: 3 \\
\hline $\begin{array}{l}\text { Sub-fascial } \\
\text { hematoma }\end{array}$ & 7 & Klebsiella: 7 \\
\hline \multirow{2}{*}{ Vault infection } & \multirow{2}{*}{12} & S. aureus: 7 \\
\hline & & Bacterial vaginosis: 5 \\
\hline \multirow{2}{*}{ UTI } & \multirow{2}{*}{24} & E. coli: 18 \\
\hline & & Klebsiella: 6 \\
\hline
\end{tabular}

Table 4: Delayed intraoperative morbidity and factors for prolonged hospital stay.

\begin{tabular}{|lll|}
\hline $\begin{array}{l}\text { Wound sepsis } \\
\text { (abdominal) }\end{array}$ & $\begin{array}{l}\text { Morbidity } \\
\text { Skin incision with } \\
\text { sepsis }\end{array}$ & 13 \\
& $\begin{array}{l}\text { Sub-fascial hematoma } \\
\text { Re-suturing of gaped }\end{array}$ & 7 \\
\hline & $\begin{array}{l}\text { Re-sumer } \\
\text { abdomen }\end{array}$ & 7 \\
\cline { 2 - 3 } & Burst abdomen & 1 \\
\hline Vault infection & Vault hematoma & 12 \\
\hline Urinary complaints & Urinary infection & 24 \\
\hline \multirow{2}{*}{$\begin{array}{l}\text { Prolonged surgery } \\
\text { time (N=41) }\end{array}$} & $\begin{array}{l}\text { Previous surgery } \\
\text { adhesions }\end{array}$ & 36 \\
\cline { 2 - 3 } & Bladder injury & 3 \\
\cline { 2 - 3 } & Burst abdomen & 1 \\
\hline Anemia & Relaparotomy & 1 \\
\hline Blood transfusion & 41 & \\
\hline
\end{tabular}

Table 5: Follow-up morbidity at 4 weeks.

\begin{tabular}{|c|c|c|}
\hline & Morbidity & $\begin{array}{l}\text { Micro } \\
\text { organisms }\end{array}$ \\
\hline \multirow[t]{2}{*}{ Wound sepsis (11) } & $\begin{array}{l}\text { Skin induration with } \\
\text { stitch abscess }\end{array}$ & $\infty$ \\
\hline & Prolene granuloma & 2 \\
\hline \multirow[t]{2}{*}{ Vault sepsis (17) } & $\begin{array}{l}\text { Foul smelling } \\
\text { discharge per vaginum }\end{array}$ & 14 \\
\hline & Vault granuloma & 3 \\
\hline \multirow{3}{*}{$\begin{array}{l}\text { Urinary infection } \\
\text { (18) }\end{array}$} & S. aureus & 12 \\
\hline & E. coli & 4 \\
\hline & Klebsiella & 2 \\
\hline \multirow{2}{*}{$\begin{array}{l}\text { Abdomen wound } \\
\text { smear (11) }\end{array}$} & S. epidermiditis & 9 \\
\hline & E. coli & 2 \\
\hline \multirow{2}{*}{ Vault smear (17) } & S. aureus & 12 \\
\hline & Bacterial vaginosis & 5 \\
\hline
\end{tabular}

Commonest causes were sepsis and urinary infection. Prolonged hospital stay was due to bladder injury, wound re-suturing and anemia. 20 women had abdominal wound sepsis, 7 needed re-suturing for gaping of wound. Burst abdomen was seen in 1 woman who had prolonged surgery time and increased blood loss. 33 women needed blood transfusion for anemia.

Follow-up at 4 weeks, 81 were morbidity free (72\%). Wound sepsis smear in 11 shows $S$. epidermidis in 9 and E. coli in 2. Urinary infection was due to $S$. aureus in 12 and E. coli in 4 and Klebsiella in 2. Vault smear (17) S. aureus in 12 and bacterial vaginosis in 5. Vault granuloma 3, histology was prolapsed fallopian tube in 2 and foreign body granuloma in 1 . More than 1 morbidity was seen in 10 women.

\section{DISCUSSION}

113 perimenopausal women in and around Ammapettai village in Kanchipuram district, Tamil Nadu who underwent abdominal (81), vaginal hysterectomy (32), in SSSMCRI were study subjects. 46 fibroids, 22 adenomyosis, 13 DUB with first degree uterine descent and $3^{\text {rd }}$ degree uterine prolapse, 22 first degree descent with DUB 10 were the indications for hysterectomies.

Table 1 shows pain morbidity. All 113 had postoperative pain. Pain was severe in abdominal hysterectomy women and they needed more analgesics. They could walk with help on third post op day, whereas, vaginal hysterectomy women walked without support on $2^{\text {nd }}$ day. Pain gradually decreased. Anand from Bombay had similar observation in his study. ${ }^{4}$

Table 2 shows early post-operative morbidity within 72 hours. Blood loss of more than $350 \mathrm{ml}$ was seen in 46 TAH and $18 \mathrm{VH}$ women (57.6\%). Blood transfusion was needed in $33(34.2 \%)$. Chabbra, Pia W have reported $10 \%$ of their patients had blood transfusions. ${ }^{1,2}$ Peripert, Makinenl $\mathrm{J}$ have quoted that $20 \%$ of their patients had increased blood loss. ${ }^{3,6}$ Thompson has reported that $15.4 \%$ of his patients had blood transfusions due to fall in hemoglobin. ${ }^{7}$ In the present study Increase in surgery time was seen in 41 women (32 $\mathrm{TAH}$ and $9 \mathrm{VH}$ ). Previous surgery adhesions were seen in 36 cases, large tumor in 20 and bladder injuries in 3 cases in the present study. ${ }^{7}$ Similar observation was reported by Authors. ${ }^{1,2,6,7}$ Anand reported, $2.3 \%$ bladder injury and Makinenl J reported ureter injury in $7.2 \%$ which resulted in prolonged surgery time and increased bleeding. ${ }^{3,4}$ In the present study bladder injuries were seen in 2 women with previous 2 LSCS scars and 1 with previous Manchester operation. Paralytic ileus was seen in 6 women, and relaparotomy was done in 1 TAH subject for intraabdominal bleeding which was also reported by Anand. ${ }^{4}$

Table 3 shows fever morbidity in 50 women (54\%). Common cause was wound sepsis. In the present study 13 had skin incision infection with discharge, 7 had subfascial hematoma, ending up with wound gaping. Fever due to wound sepsis, sub-fascial hematoma and wound gaping is being reported by authors. ${ }^{1,3,4,5,9} 40 \%$ of 
Antonelle's patients had wound sepsis and gaping which is higher than our observation. Second cause of fever was vaginal vault infection. ${ }^{5}$ Pelvic fluid collection was seen in 12 of our cases who had fever and vaginal discharge. Antonelle's has reported 10 percent of his vaginal hysterectomy patients had pelvic fluid collection, fever and vaginal discharge. ${ }^{5}$ Third important fever morbidity was due to urinary infection. In $20 \%$ of our cases $(n=24)$. E. coli was seen in 18 and Klebsiella in 6. Fever due to urinary infection is also reported by others like Makinenl J, Antonelle's (10\%), Person E and Karthika (3.6 percent) in their study. ${ }^{3,5,9,10}$ E. coli infection was the commonest in all studies.

Table 4 shows delayed intra-operative morbidity and risk-factors for prolonged hospital stay. Microbiology results showed that common microorganisms seen in skin wound smear were $S$. aureus 10 in 9 and $E$. coli 10 in 2 cases respectively. 12 Vaginal vault smears showed $S$ aureus in 7 and Bacterial vaginosis in 5 cases respectively. Vault infection with vault hematoma 7 in 12 cases, were confirmed by pelvic fluid collection. ${ }^{5}$ Presence of bacterial vaginosis was reported by other authors in vault cuff infection and found bacterial vaginosis as an important risk factor for fever morbidity. ${ }^{8-}$

11 Risk factors for delayed morbidity and prolonged hospital stay were, wound sepsis with induration in 13 and gaping due to sub-fascial hematoma which needed re-suturing in 71 cases respectively. ${ }^{4,7,9}$ Urinary infection was seen in 24 cases. Commonest was E. coli ${ }^{10}$ In the present study 36 previous surgery adhesions, 3 bladder injuries, one burst abdomen and one relaparotomy were seen. ${ }^{3,4,6,9} 33$ out of 41 women had blood transfusion due to increased blood loss which is also reported by authors. ${ }^{1-4,7,9} 41$ women had more than 10 days stay in our hospital. UTI as a cause of fever morbidity is reported by authors Anand, Juha, Antoneille, Person E and Karthika1.3,4,5,9,10 Prolonged surgery time with increased bleeding was seen in 41 women $(36 \%)$.

Table 5 shows follow-up morbidity at 4 weeks. In women who came with fever and vaginal discharge, skin wound smear and vaginal vault smear were taken. Wound infection was seen in 9 and prolene granuloma in 2 cases. Vaginal vault infection was seen in 14. Foul smelling blood stained discharge was seen in 3 cases. Per speculum examination showed ulcerative lesion on the vault. Biopsy was taken. Histopathology report was prolapsed fallopian tube in 2 cases and 1 foreign body granuloma. Anand reported 2 cases and Silverberg 4 cases respectively. ${ }^{4,11}$ Urinary infection was seen in 18 cases with $E$. coli infection in 4 Klebsiella in 2 and $S$. aureus in 12 cases respectively. Commonest organism was $S$. aureus 10. Abdominal wound smear showed Staphylococcus epidermidis 6 and E. coli $10 .^{3}$ In vault smear $S$ aureus 12, Bacterial vaginosis 5, was seen. ${ }^{10}$ Larson, Person, and Karthika have also reported bacterial vaginosis in vaginal cuff infections. ${ }^{8-10}$ Bacterial vaginosis is one of the important risk factors in post hysterectomy morbidity. Staphylococcus was the commonest organism seen in wound and vault infection in the present series which corresponds to Karthika's observation.

\section{CONCLUSION}

This prospective observational study conducted among rural women belonging to poor socioeconomic strata revealed their lack of awareness regarding health needs and available health facilities. Out of 81 women who had abdominal hysterectomies, 46 had uterine fibroids, average size was 24 weeks in 20 cases. 60 patients presented with anemia less than $7 \mathrm{~g}$ hemoglobin. 24 had urinary infection (E. coli 18 and Klebsiella 6). Vaginal infection due to Staphylococcus aureus in 13 and bacterial vaginosis in 5.49 abdominal scars of which 9 had 2 caesarian section and 14 had 1 caesarian section. Tubectomy scar was seen in 20 , and appendicectomy scar in 6 .

50 postoperative women had fever, 33 needed blood transfusions. 7 needed re-suturing of skin incision. 1 burst abdomen, 1 relaparotomy and 3 bladder injuries were reported. 41 women had prolonged hospital stay. 36 women had more than 1 morbidity.

In follow-up morbidity at 4 weeks $72 \%$ (81 cases) were morbidity free. Skin incision infection in 9, prolene granuloma in 2, vaginal discharge in 14, vault granuloma 3 and UTI in 18 cases respectively. Vault smear showed 5 bacterial vaginoses, 9 staphylococcus aureus infection and 3 E. coli.

Pre-op assessment and treatment for morbidity risk factors like anemia, urinary and vaginal infections is mandatory. Awareness of problems to be faced, anticipation of complications due to size, site and number of tumor, previous post op adhesions and timely intervention by experienced surgeons with adequate blood transfusion reduces morbidity.

Funding: No funding sources

Conflict of interest: None declared

Ethical approval: The study was approved by the Institutional Ethics Committee

\section{REFERENCES}

1. Chhabra S, Kutchil, Bhavani M, Mehta S. Trends in morbidity, mortality associated with hysterectomy for benign gynecological disorders in low resource settings. Health Review. 2015;11(2):152-6.

2. Wong PI, Thonkhamrop J, Seejornt, Bappasiri P. Incidence of and risk factors for febrile morbidity after laparoscopic assisted vaginal hysterectomy. Dovepress. 2014;2014:6.

3. Mäkinen J, Johansson J, Tomás C, Tomás E, Heinonen PK, Laatikainen T, et al. Morbidity of 10 110 hysterectomies by type of approach. Human Reproduction. 2001;16(7):1473-8. 
4. Nanavati AM, Gokral SB. A prospective randomized comparative study of vaginal, abdominal and laparoscopic hysterectomies. J Obstet Gynecol Ind. 2016;66(s1):s381-94.

5. Antonelli E, Morales MA, Dumps P, Boulvain M. Sonographic detection of fluid collection and postoperative morbidity following cesarian section and hysterectomy. Ultrasound Obstet Gyenecol J. 2004;23(4):388-92.

6. Peripert, Jeffrey F, Weitzen, Sherry. Risk factors for febrile morbidity after hysterectomy. Obstet Gynecol. 2004;103(1):86-91.

7. Thomson AJ, Sproston AR, Farquharson RG. Ultrasound detection of vault haematoma following vaginal hysterectomy. Int $\mathbf{J}$ Obstet Gynaecol. 1998;105(2):211-5.

8. Larsson PG, Platz-christensen JJ, Forsum U, PÅhlson C. Clue cells in predicting infections after abdominal hysterectomy. Obstet Gynecol. 1991;77(3):450-2.
9. Persson E, Bergström M, Larsson PG, Moberg P, Platz-christensen JJ, Schedvins K, et al. Infections after hysterectomy a prospective nation-wide Swedish study. Acta obstetricia et gynecologica Scandinavica. 1996;75(8):757-61.

10. Jeyakumar K, Sheela W, Lakshmi SJ, Panduranga S, Mohanambal M. Microbial vaginitis in reproductive women of silk city of south India. Int J Current Microbiol Applied Sci. 2016;5(2):272-8.

11. Silverberg SG, Frabh W. Prolapsed of fallopian tube into vaginal vault after hysterectomy. Arch Pathol. 1974;97:100-8.

Cite this article as: Lakshmi PV, Sheela WG, Munusamy MM. Post Hysterectomy morbidity: a suburban teaching hospital experience in Kanchipuram, Tamil Nadu, South India. Int J Reprod Contracept Obstet Gynecol 2017;6:4656-60. 